\title{
"UNO YA SABE A LO QUE VIENE": LA MOVILIDAD LABORAL DE MIGRANTES ANDINO-BOLIVIANOS ENTRE TALLERES DE COSTURA DE SÃO PAULO EXPLICADA A LA LUZ DE LA PRODUCCIÓN DEL CONSENTIMIENTO
}

\author{
"One already knows what's coming": labor mobility of Bolivian andean \\ migrants within sweatshops in São Paulo under manufacturing \\ consent approach
}

Bruno Miranda

\begin{abstract}
Resumen. El presente trabajo tiene sus lentes puestos en la movilidad de migrantes de la región andina de Bolivia hacia los talleres de costura ubicados en la zona metropolitana de São Paulo, Brasil, recorrido que hacen a lo largo de por lo menos veinticinco años. El objetivo es problematizar las relaciones laborales entre los costureros y los talleristas (los gestores de los talleres) más allá de la victimización de estos grupos de migrantes, considerando ciertos niveles de coerción, pero también de consentimiento - todo lo anterior bajo determinadas formas de trabajo no-libre. El mecanismo de producción del consentimiento se sustenta en elementos institucionales e ideológicos que en última instancia definen los "límites de la esclavitud".
\end{abstract}

Palabras clave: migración boliviana, trabajo esclavo, trabajo no-libre, producción del consentimiento.

\begin{abstract}
This article addresses issues regarding labor mobility of Bolivian Andean migrants towards sweatshops located in the metropolitan area of São Paulo, Brazil. This is the journey they have been enduring over the last twenty-five years. This work analyses labor relations between sewers and sweatshop managers beyond usual victimization against migrant groups from Bolivia, taking into account both coercion and consent levels - all of which under forms of unfree labor. The mechanism of manufacturing consent is supported by institutional and ideological elements which define the "slavery boundaries" at last instance.
\end{abstract}

Keywords: Bolivian migration, slave labor, unfree labor, manufacturing consent.

\footnotetext{
1 Departamento de Ciências Sociais, Universidade Federal da Fronteira Sul. Chapecó, SC, Brasil.
} 


\section{Introducción}

A partir de los años noventa por lo menos, la movilidad de migrantes, especialmente desde la región andina de Bolivia, ha nutrido de costureros y de costureras a incontables talleres de costura del área metropolitana de São Paulo, Brasil. Son por lo menos veinticinco años de una circularidad migratoria que se desarrolla bajo condiciones específicas de contratación y de empleo, las mismas que política y públicamente han sido tratadas como trabajo esclavo o entonces como "condiciones análogas a la esclavitud" por parte de entidades estatales, civiles y ONG. No obstante los más de diez años de combate por parte de los grupos municipal, estatal y federal de erradicación del trabajo esclavo, las situaciones de encierro, retención de documentos, amenazas y malos tratos, que venían arrastrándose desde los años noventa, siguen reproduciéndose².

La continuidad de las denuncias y la gravedad de lo que expresan dan cuenta de una dinámica de funcionamiento de parte de la industria de la moda más propensa a relaciones laborales coercitivas. La extensión de las jornadas laborales, de quince horas diarias o más, el ritmo imparable de la confección, así como la ausencia de sindicatos y de beneficios laborales mínimos refuerzan dicha idea. Sin embargo, la dinámica de inserción laboral que la noción de trabajo esclavo oculta no es simple. Resulta curioso observar que no obstante la comprobación de aspectos coercitivos, esta movilidad laboral sigue ininterrumpida.

Para ayudar a comprender este proceso, han sido producidos decenas de artículos y tesis a lo largo de las últimas dos décadas, cuando menos. Este material ha variado, hasta hace poco, desde la problematización de la estigmatización étnico-racial de los grupos andinos ${ }^{3}$, al análisis del proceso de subcontratación de talleres de costura con y sin migrantes ${ }^{4}$. La sistematización de la información revela la existencia de deudas entre los talleristas (gestores del taller) y los costureros que suelen implicar restricciones de libertad. Recientemente, otro material ha aportado a la discusión sobre la existencia de agencia del migrante, ya sea a través de una negociación del traslado, realizada antes de la llegada del migrante a São Paulo", o entonces del "funcionamiento del mecanismo que hace que los trabajadores circulen y se fijen, y que formen un mercado y una fuerza de trabajo dispuesta, operando un complejo proceso de subjetivación" ${ }^{\prime 6}$.

2 Cf. Suspeita de trabalho escravo faz PM libertar bolivianos em São Paulo. O Estado de São Paulo, 12.10.2014.

3 Cf. SILVA, Sidney da. A migração dos símbolos: diálogo intercultural e processos identitários entre os bolivianos em São Paulo.

4 Cf. FREIRE DA SILVA, Carlos. Trabalho Informal e Redes de Subcontratação: Dinâmicas Urbanas da Indústria de Confecções em São Paulo.

5 Cf. FREITAS, Patricia de. Projeto costura. Percursos sociais de trabalhadores migrantes, entre a Bolívia e a indústria de confecção das cidades de destino.

6 CORTES, Tiago. Os migrantes da costura em São Paulo: retalhos de trabalho, cidade e Estado, p. 179. 
También sigo la sugerencia de Sylvain Souchaud, para quien "los talleres de costura no pueden ser considerados únicamente como lugares de explotación de mano de obra inmigrante" ${ }^{\prime \prime}$, sino también de la internalización de cierta institucionalidad que beneficia desigualmente a talleristas y a costureros.

Contrarios a la imagen de "pueblo sufrido", los representantes de grupos de apoyo al migrante plantean que el boliviano no se siente satisfecho con los términos "esclavo" o "pobrecito". Entre las conversaciones formales e informales que he mantenido, es permanente la idea de que uno ya sabe a lo que viene, es decir, el migrante boliviano arriba a São Paulo a sabiendas del funcionamiento general de los talleres de costura. Zacarías Saavedra, profesional de la radio y agente social, lo ratifica a su manera.

Dice:

Aunque no me creas, iuno mismo se somete a esto! Mi vecino, por ejemplo, entra a trabajar a las $6 \mathrm{~h}$ de la mañana hasta la medianoche. iPero él es solito con su esposa! Si entrara a las $8 \mathrm{~h}$ hasta las $17 \mathrm{~h}$, no le cubre el costo, lo que le pagan. No están bien informados, el tallerista no tiene información sobre las leyes ni nada, a él le hicieron trabajar así y él piensa que es la norma, los coreanos iniciaron esto y los bolivianos le siguieron. Porque si tú vas a Bolivia, no hay, ino hay este sistema en Bolivia! Este trabajo de esclavo no existe allá8.

Todos estos elementos fundamentan la suposición de un cierto "límite de la esclavitud", es decir, una frontera, no fija ni transparente, entre elementos de coerción por parte del tallerista y de consentimiento por parte del costurero, que generan arreglos laborales desiguales, pero con participación activa de ambas partes. En el cruce entre la sociología del trabajo y la sociología de las migraciones, este texto problematiza la continuidad de esta movilidad tomando como punto de partida la institucionalidad erigida entre los miembros del taller.

Fruto de una tesis doctoral ${ }^{9}$, este texto indaga sobre la participación, desde luego subyugada, del propio migrante costurero en el proceso de dominación de su fuerza de trabajo. La elaboración de dicha tesis incluyó un trabajo de campo en el centro de São Paulo entre 2012-2016, y una etnografía de piso, realizada en talleres de costura con migrantes andino-bolivianos que proveen prendas a la llamada Feirinha da Madrugada ${ }^{10}$ y a las tiendas del barrio Bom Retiro. En uno de ellos, me integré como un costurero más, y a lo largo de un mes compartí trabajo y vivienda con otros seis costureros del área metropolitana

SOUCHAUD, Sylvain. A confecção: nicho étnico ou nicho econômico para a imigração latinoamericana em São Paulo?, p. 80.

8 Entrevista a Zacarías Saavedra, 04.02.2015.

9 Tesis doctoral titulada Entre coerción y consentimiento: la circulación de trabajo no-libre boliviano visto desde un taller de costura de Bom Retiro, Sao Paulo, presentada en el Programa de Posgrado en Ciencias Políticas y Sociales de la Universidad Nacional Autónoma de México/UNAM, 2016.

${ }^{10}$ Es el espacio emblemático del circuito inferior, en el barrio del Brás. 
de La Paz y sus hijos. La etnografía me permitió una convivencia en momentos de confección; de otra manera, esto se resumiría a los momentos de descanso, los domingos, cuando están lejos de la máquina de costura.

\section{Acerca de la morfología no-libre del trabajo en el taller}

El tallerista arma distintos arreglos familiares y laborales en el espacio de su taller de costura. Ya sea que la relación de parentesco se exprese de forma directa (como en la contratación de hijos, sobrinos, primos), extendida (cuando contrata a compadres y ahijados) o que simplemente no exista (cuando lo hace con amigos o paisanos), al volverse empleador, el tallerista también se vuelve padrino. El padrinazgo, entendido formal o informalmente, es de esta forma el corolario de la acción de ofertar traslado y empleo al migrante recién-llegado. En todos estos casos, el acuerdo entre el tallerista y el costurero implica una remuneración. Aunque es afectada por lazos de dependencia relativos al ámbito de la reproducción de la fuerza de trabajo, se espera a fines del mes una retribución monetaria correspondiente a la cantidad de prendas de vestir confeccionadas. Por lo anterior, la dinámica de contratación y de empleo de migrantes trae a colación formas de trabajo asalariado no-clásicas, que impiden la libre movilidad del costurero e involucran niveles de coerción que son extraeconómicos.

La clasificación de trabajo "libre" o "no-libre" dependerá, de esta manera, de la calidad del mecanismo de coerción que empuja al costurero o costurera a ejercer sus funciones. Si lo que está en juego es el mismo empleo, de lo que se trata es de coerción económica, justamente la que se relaciona con el trabajo libre asalariado. Por otro lado, si el grado de coerción es tal que implica "la incapacidad efectiva del trabajador de interrumpir su trabajo o buscar otro empleo, o entonces abandonar completamente el trabajo actual"11, lo que se tiene son condiciones de trabajo no-libre. En la misma senda, Tom Brass ${ }^{12}$ plantea que el trabajo temporal migrante suele tener componentes no-libres, especialmente en el marco de las reestructuraciones productivas emprendidas por el capital a nivel global. Pareciera ser el caso de la industria de la moda de São Paulo. Su reestructuración, a fines de los años sesenta ${ }^{13}$, ha estado basada no sólo en la contratación a distancia que implica deudas referentes al traslado, sino en la combinación entre local de trabajo y vivienda.

Otro autor que participa en el debate sobre el trabajo en clave no-libre es Yann Moulier-Boutang, para quien el trabajo no-libre abunda y se desarrolla

\footnotetext{
11 MCGRATH, Siobhán. Unfree labor, capitalism and contemporary forms of slavery, p. 3, traducción propia.

${ }^{12}$ BRASS, Tom. Labour Regime Change in the Twenty-First Century: Unfreedom, Capitalism and Primitive Accumulation.

${ }^{13}$ Cf. KONTIC, Branislav. Inovação e redes sociais: A indústria da moda em São Paulo. Tesis de Doctorado, USP, 2007.
} 
lado a lado del trabajo libre. Juntos, se interpenetran y se complementan, dándole oxígeno al desarrollo capitalista. Es por ello que

una teoría de las formas de trabajo no-libre no puede escapar a una teoría del trabajo asalariado. La excepción debe ser entendida en su desviación de un estándar y, por lo tanto, es necesario producir una teoría de la transformación de las dos formas la una en la otra, en ambas direcciones ${ }^{14}$.

Según este autor, hay dimensiones graduales de proletarización, entre las cuales la "proletarización radical" es exactamente la que se plasma en el trabajo migrante internacional, sin derechos civiles y políticos. El autor plantea lo anterior con base en procesos de países europeos, como Francia y España, que cuentan con regímenes de trabajo y permanencia de migrantes especiales y temporales.

La noción de trabajo no-libre entonces no reivindica la figura del esclavo y le da otros matices a la dependencia del trabajador hacia su empleador, permitiendo articular la coerción económica, típica del trabajo asalariado, con tipos de coerción extraeconómica. El proceso productivo de prendas de vestir en talleres de costura de São Paulo parece combinar estos tipos de coerción. En la medida que son relaciones capitalistas, tienen obviamente su grado de coerción económica, pero incluyen normas tácitamente instituidas y practicadas por todos los miembros del taller. Son tácitas justamente porque no tienen expresión legal.

\section{Sobre cómo opera la no-libertad}

Quisiera destacar inicialmente tres aspectos no-libres de trabajo que se pudo observar de forma general, según Brass ${ }^{15}$ y McGrath ${ }^{16}$. El primero de ellos es el vínculo laboral por deuda. Se trata del control de la fuerza de trabajo mediante deuda contraída por parte del trabajador. La deuda suele ser saldada con trabajo gratuito por parte del migrante, es decir, con ausencia de pago durante semanas o meses. En el taller de costura, bajo control exclusivo del tallerista, este vínculo por deuda se extiende sin límites definidos claramente en el tiempo.

Una variación de esta forma es el vínculo por adelanto de salario en efectivo. En la jerga de los talleres de costura, se le conoce como vale. Los vales son entregados cada fin de semana al costurero para que salga a la calle a pasear, a comer o a beber algo, especialmente los domingos. En todos los talleres de costura con los cuales tuve algún tipo de interlocución, los vales correspondían a cerca de $U \$ 15$, los cuales eran debidamente apuntados en fichas de control del tallerista, para que fueran restados del pago a fines del mes. Se trata de una manera más de "atar" al trabajador por medio de pagos parciales anticipados.

\footnotetext{
${ }^{14}$ MOULIER-BOUTANG, Yann. Formes de travail non libre. Accumulation primitive: préhistoire ou histoire continuée du capitalisme?, p. 1070, traducción propia.

15 BRASS, op. cit.

${ }^{16}$ MCGRATH, op. cit.
} 
La tercera y última forma que quisiera destacar es el aprendizaje, a través de la cual se intercambia la enseñanza de un oficio por horas de trabajo no pagado. En el sentido estricto del término, es otro intercambio desigual, enmarcado en una dinámica que en los talleres de costura involucra no raras veces a padrinos y a ahijados, a tíos y a sobrinos, a papás y a hijos, a parientes cercanos o extendidos. En estos casos, se trata de un tipo de relación basada en el parentesco que oculta condiciones abusivas de acuerdo laboral, en las cuales la autoridad del padrino, del tío o del padre, se sobrepone a los derechos de sus parientes empleados. De hecho, las tres formas (la deuda, los vales y el aprendizaje) muchas veces se combinan y refuerzan la solidez y el grado del vínculo laboral, especialmente para costureros y costureras recién-llegadas, cuyo periodo para saldar la deuda contraída puede alargarse en el tiempo debido a que eventualmente son aprendices. En otros casos, la existencia de deudas referente al traslado también puede combinarse con los vales solicitados por el costurero, aumentando su monto.

Los y las costureras no tienen una relación específicamente asalariada. Tienen, más bien, una relación asalariada con componentes no-libres de trabajo. Son relaciones productivas constreñidas a institucionalidades desarrolladas entre los talleristas y los costureros, que resultan en la imposibilidad de facto de la locomoción del trabajador migrante entresemana, de lunes a viernes. Son varios los elementos que determinan dicha imposibilidad. Por un lado, el empleador exige permanencia en el taller y por el otro, al costurero no le conviene "perder tiempo paseando o descansando", porque cobra por prenda confeccionada. Además, perder un puesto como costurero no implica sólo conseguir otro taller donde trabajar. Cuando se rompe la relación laboral con un taller, se está rompiendo con las coerciones extraeconómicas existentes en este espacio, como la alimentación y la vivienda. Con todo lo anterior, pareciera entonces que los márgenes de maniobra del tallerista son amplios, y verdaderamente lo son. Sin embargo, contradictoriamente, esta indefinición también genera espacios de acción para el costurero.

El espacio de acción migrante se abre en un primer momento en la adhesión o no a la oferta de empleo. Antes de trasladarse al taller de destino en São Paulo, está abierta la posibilidad para que el trabajador simplemente rechace la propuesta de trabajo. En los términos que quisiera destacar, el accionar migrante se expresa en la adhesión voluntaria a un determinado trabajo o actividad. Es una acción positiva justamente porque se podría esperar que contestara negativamente o simplemente no adhiriera. Al aceptar la oferta de trabajo, sigue habiendo espacios de elección, relativos por ejemplo al carácter estacional de la industria de la moda. Los periodos de baja en el mercado, cuando hay menos paquetes de prendas para la confección (en general a inicios de año), son también momentos de suspensión del trabajo en 
el taller de costura. Ello porque no sólo el tallerista aprovecha para trasladarse a Los Andes para recoger a más empleados personalmente, como también el costurero tiene más flexibilidad en su jornada laboral, en virtud de que hay menos piezas de ropa para coser.

Aun considerando elecciones forzadas, se contempla una suerte de interacción entre dominador y dominado, entre estrategias de los de arriba y los valores y los roles asumidos por los de abajo, que al final terminan por consolidar posicionamientos desiguales. Pareciera, por lo tanto, que el encierro en el taller es impulsado antes por el disciplinamiento de la fuerza de trabajo migrante a lo largo de casi tres décadas, que por arbitrariedades del empleador. Es, por decirlo de alguna manera, encierro consentido.

\section{El mecanismo de producción del consentimiento}

En ese contexto, lo que supongo es la existencia de un esquema articulado y específico de coerción objetiva y visible por un lado, y de conductas activas por parte de estos grupos de migrantes por el otro, que terminan por hacer posible una dinámica permeada por características de trabajo asalariado no-libre. Con el fin de profundizar aspectos concernientes a la participación activa del costurero en sus mismas restricciones de movilidad, recurro a Michael Burawoy $^{17}$, quien plantea la existencia de mecanismos materiales e ideológicos de involucramiento del trabajador en el proceso productivo en el marco de lo que denomina la producción del consentimiento. Para tal tarea, Burawoy toma en cuenta los cambios en la organización del trabajo a partir de los años setenta, especialmente los relativos a la interiorización de la competencia externa, entre las empresas, hacia el proceso productivo, entre los trabajadores. El proceso de interiorización que analiza tiene su foco en EEUU, pero ha implicado, a lo largo de los años, la globalización del pago por productividad (o pago a destajo), al tiempo que supone un control mayor del proceso productivo por parte de los mismos. Es así que el consentimiento se genera a partir de la ampliación de la autonomía obrera en el ámbito de la producción, expresada por ejemplo en la determinación de la duración de su propia jornada laboral y del número de piezas producidas por jornada.

Puesto lo anterior, describiré los elementos materiales/institucionales de la producción del consentimiento entorno a lo que Burawoy concibe como (1) el sistema de gobierno interno a la empresa, cuyo resultado en el taller es vincular el migrante costurero a su local de trabajo, articulando sus intereses a los intereses del tallerista. Posteriormente, analizaré los elementos ideológicos de este proceso, centrados en lo que el autor define como (2) el mercado

\footnotetext{
17 BURAWOY, Michael. El consentimiento en la producción. Los cambios del proceso productivo en el capitalismo monopolista.
} 
laboral interno. Es lo que determina la distribución de los puestos de trabajo y de ascensión laboral en el taller de costura. La tercera y última pieza material en la producción del consentimiento tiene que ver con la dinámica generada en el seno de las relaciones sociales propia de (3) un juego. El juego concreto consiste en la manipulación de las relaciones en el taller de costura por parte del migrante, con el fin de sacar de éstas beneficios para soportar las privaciones propias de su condición. Es la forma de adaptación del obrero a su proceso productivo, una vez que sus reglas son impuestas y de las cuales no participa en condición de formulador.

Este planteamiento general permite analizar la complejización de las formas de dominación en el taller de costura, tomando en consideración el margen de acción del migrante, su poder de decisión mediante consentimiento activo, aún a sabiendas que los intereses del tallerista se enfrentan a sus propios intereses.

\subsection{Los "límites de la esclavitud"}

La institucionalidad erigida es la base material de la producción del consentimiento, noción que, reitero, ayuda a explicar la continuidad de la circulación de sujetos migrantes a lo largo de más de dos décadas, bajo aspectos no-libres de trabajo. El conjunto de instituciones que comentaré enseguida forma el sistema de gobierno del taller y opera por detrás de lo verbalmente acordado; es lo que define en última instancia los límites del acuerdo tácito entre los talleristas y los costureros. Estos acuerdos, cuando no son respetados por parte del tallerista, pueden llevar a la ruptura de relación laboral por parte del costurero.

La primera de las instituciones tiene carácter transnacional. En el escenario andino de Bolivia, el joven que se dirige del campo a las ciudades-eje, tales como El Alto, vecina a La Paz, lo hace en condición de trabajador rural recién-llegado y de aprendiz, en general respaldado por un pariente. Esto significa que para tener el derecho a su lugar en la ciudad y a aprender un oficio, deberá trabajar sin remuneración a principio. Es como un intercambio de favores con el que le ofrece trabajo y techo en la ciudad. Entendido como rito de paso, suele involucrar a parientes cercanos o extendidos, quienes reclutan a sus futuros empleados desde el campo para que inicien su ciclo de vida urbano. A esta práctica en Bolivia se le conoce como derecho de piso ${ }^{18}$.

El derecho de piso se agrava en contextos migratorios internacionales. Eso debido a que el sujeto migrante deberá hacer frente a la deuda de un traslado más costoso, y enfrentar hostilidades propias de localidades que le son ajenas,

${ }^{18}$ CUSICANQUI, Silvia Rivera et alii. De chuequistas y overlockas: una discusión en torno a los talleres textiles. 
como el idioma o los códigos de conducta distintos a los suyos. El derecho de piso también puede ser activado más de una vez sobre los migrantes que van y vuelven al área metropolitana paulista. Me explico: el recién-llegado puede ser un aprendiz sin experiencia en la costura, quien llegará a su destino por primera vez, o entonces el individuo experimentado quien ha decidido regresar a São Paulo por segunda vez. Aunque ya tenga calificación en la costura, pero siempre y cuando no pueda pagar su traslado, el derecho de piso será reactivado.

Dicha institucionalidad, trasladada y trasmutada a talleres de São Paulo, le da al tallerista un margen de maniobra que le permite el control de la fuerza de trabajo, así como de la movilidad del costurero, sin tener que acudir a elementos únicamente coercitivos en primera instancia. Se trata de una institucionalidad irregular, propia de un acuerdo extra-oficial. Esto no quiere decir que no haya límites o entonces que el control de la fuerza de trabajo sea absoluto. El límite se rompe cuando, por ejemplo, el periodo de derecho de piso se extiende en el tiempo, o cuando simplemente se les retiene el salario por meses sin ofrecerles una explicación. De parte del costurero, hay cierta incorporación de los derechos y de las obligaciones, pero cuando las obligaciones se sobreponen más allá del derecho de piso, suelen ser contestadas mediante la fuga del taller y/o la denuncia ante órganos de la sociedad civil. De esta forma, lo que define la quiebra del acuerdo son las conductas del tallerista no consentidas por el costurero.

Otro de los derechos instituidos se refiere a lo que en los talleres de costura de bolivianos en Argentina se conoce como sistema de cama-caliente ${ }^{19}$. Este sistema hace alusión a la convergencia de producción y reproducción de la fuerza de trabajo en un mismo espacio. Desde el punto de vista del costurero, trabajar y vivir en el mismo local permite ahorrar recursos con transporte y renta. Su condición de migrante y de trabajador temporal ayuda a explicar su adhesión a dicho esquema. Sin embargo, vivir y trabajar en el mismo local suele implicar no ver la luz del día a no ser por entre las ventanas del taller. También implica estar atado quince o más horas en una misma posición, sin ni siquiera abrir la puerta del taller para salir a la calle entre semana. Es justamente ahí cuando aspectos coercitivos no son lo suficiente para explicar por qué lo hacen.

Tener empleo, techo y comida seguramente pesa en el cálculo del costurero recién-llegado, pero el sistema de cama-caliente va más allá de ello. Me refiero a que este sistema involucra a los miles de costureros voladores. En la jerga de los talleres, el volador es el migrante que se encuentra en São Paulo y "vuela" de un taller de costura a otro, cuando decide cambiar a un local de trabajo que le ofrece más beneficios, o cuando es forzado a hacerlo por conflictos con el tallerista.

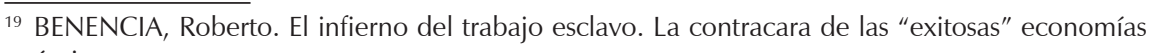
étnicas. 
En general, el volador ha superado el derecho de piso, pero al cambiar de taller, sigue viviendo y trabajando en el mismo espacio. Así como el derecho de piso transnacional, la forma cómo se procesa el sistema de cama-caliente puede delimitar lo que es coerción y lo que es consentimiento. Es decir, muchos migrantes son conscientes de que van a trabajar y vivir en el mismo local, pero no siempre eligen dónde descansar para reponer su energía. Tampoco eligen las condiciones de lo que supone es su espacio de privacidad (su cuarto de dormir), así como la calidad y cantidad de comidas al día, ya que el costurero se alimenta dependiendo de lo que el tallerista le ofrezca de comer.

Es así que el sistema de cama-caliente puede derivar en conductas no consentidas, especialmente cuando hay engaño por parte del tallerista con relación a los aspectos de la vivienda y de la alimentación. Así como el derecho de piso transnacional, el sistema de cama-caliente delimita la frontera del acuerdo tácito. $\mathrm{O}$ de lo que es esclavitud o no, en los términos del sentido común promovido por defensores de los derechos humanos. Se puede inclinar a la coerción abierta o al consentimiento, dependiendo de su forma concreta.

La tercera institucionalidad que sienta las bases materiales del consentimiento es la práctica del adelanto de sueldo en efectivo, expresada en los vales. Al parecer, no sólo el vale ha sido institucionalizado, sino su monto por fin de semana. Los vales se erigen como otra herramienta de control de la movilidad del costurero por parte del tallerista. No se puede ir muy lejos con U\$15 en el bolsillo en un domingo en una ciudad costosa como São Paulo. Los voladores que llegan a un nuevo taller, sin ahorros, o aquellos cuyo sueldo anterior ha acabado antes del fin del mes, suelen pedir vales en todos los fines de semana. Lo hacen especialmente los recién-llegados, bajo el derecho de piso, quienes además de la deuda ya contraída por el traslado a Brasil, deberán hacer frente a los montos correspondientes a los vales, que refuerzan el vínculo por deuda. Es así que la institución del vale acaba por nutrir y prolongar el periodo de derecho de piso.

Estos tres elementos conforman la materialidad del consentimiento y definen los "límites de la esclavitud", es decir, definen la frontera entre lo aceptado y lo no aceptado, bajo condiciones de trabajo no-libre. Los aspectos consentidos en los talleres de costura son justamente aquellos socialmente aceptados por parte de los costureros y de los talleristas. Considero este proceso como una puerta de entrada que revela no sólo la dominación objetiva, sino la participación activa del costurero en dicho proceso. Por otro lado, las conductas que van más allá de esos límites se encuadran dentro de los elementos coercitivos, o no consentidos, es decir, aquellos que no hacen parte del acuerdo tácito entre el tallerista y el costurero, y por lo tanto, no participan en la producción del consentimiento (véase Cuadro 1). 


\section{Cuadro 1 - Elementos del consentimiento y no consentidos del trabajo no-libre en talleres de costura}

\begin{tabular}{c|c}
\hline $\begin{array}{c}\text { Formas consentidas } \\
\text { (elementos del consentimiento) }\end{array}$ & $\begin{array}{c}\text { Formas no-consentidas } \\
\text { (elementos de coerción) }\end{array}$ \\
\hline $\begin{array}{c}\text { Derecho de piso transnacional } \\
\text { (aprendizaje y/o vínculo por deuda) }\end{array}$ & $\begin{array}{c}\text { Prolongación indefinida } \\
\text { del derecho de piso transnacional }\end{array}$ \\
\hline Sistema de cama-caliente & $\begin{array}{c}\text { Sistema cautivo } \\
\text { (cobro de alimentación) }\end{array}$ \\
\hline Vales & Retención de pagos \\
\hline
\end{tabular}

Fonte: Elaboración propia.

Estos elementos generan matices importantes porque posibilitan indagar, por ejemplo, si la contratación y el empleo de esos sujetos migrantes pudieran efectivamente reproducirse por más de dos décadas y media en caso de que las situaciones de coerción extrema y de arbitrariedades por parte de los talleristas fueran generalizables hasta la actualidad.

\subsection{Las bases ideológicas del consentimiento}

Además de su base material/institucional, la producción del consentimiento despliega herramientas ideológicas. La existencia de un mercado laboral interno al taller de costura, definido por los distintos puestos de trabajo, hace que el costurero pueda anhelar, por ejemplo, a ascender al siguiente puesto de trabajo. De esta forma, el mercado de trabajo interno cumple la función de interiorizar la competencia del mercado externo (la que se da entre los talleres de costura), hacia los mismos costureros.

Desde abajo hacia arriba, la estructura de los puestos de trabajo empieza con el ayudante de taller, en general joven y recién-llegado, en condición de aprendiz, quien asume tareas básicas y repetitivas vinculadas con la preparación de telas previa a la confección, o la revisión de las prendas listas. El ayudante suele cobrar menos y anhela ascender en la "escalera de la moda" 20 al puesto de rectista u overloquista ${ }^{21}$, por lo que podrá obtener un ligero aumento en la participación del pago por cada prenda confeccionada. La ascensión laboral puede ser catalizada por el matrimonio. Es de hecho lo que ocurre entre parejas, cuyo proyecto migratorio involucra tener su propio taller. En el caso de los talleres mejor estructurados, suele haber una cocinera, en general una mujer quien se encarga de las comidas diarias y a menudo de los servicios de limpieza del taller. En estos casos, igualmente suele haber un capataz, quien cumple la función de supervisar el trabajo de los demás. Es en general un pariente o alguien de la confianza del tallerista.

\footnotetext{
${ }^{20}$ Utilizo la noción de escalera con el mismo fin metafórico de Benencia (op. cit.) utiliza para describir la inserción de bolivianos en la producción de hortalizas en el conurbano bonaerense.

${ }^{21}$ Operadores de máquina recta y overloque, respectivamente.
} 
El tallerista es el propietario de las máquinas de costura del taller. Es quién contrata, distribuye las prendas y los tipos de corte y costura entre los costureros y es además quien gestiona la contabilidad de la unidad productiva, definiendo qué porcentaje del pago corresponde a cada costurero, a la manutención del taller y a su propia familia. Si es casado, comparte la tarea con su pareja, su seguidora $^{22}$. Para el tallerista, además de mantener las cuentas de su taller en día, hay que cuidar para que no falten alimentos para preparar las comidas necesarias a los costureros y a su familia, que no falten hilos para las máquinas y avíos para las prendas que los necesiten. Estos son aspectos del cotidiano, mucho menos ambiciosos que los proyectos de ampliación del número de empleados, del número de máquinas de costura, o de escapar de la dependencia de las marcas de ropa para las cuales confecciona su taller. El tallerista tiene el propósito principal de insertarse o mantenerse en el circuito de pedidos de prendas. La dinámica de ascensión sociolaboral está graficada en la Figura 1.

\section{Figura 1 - Elementos del mercado laboral en los talleres de costura con migrantes}

\section{Escalera de la Moda}

(aspectos del mercado laboral circulatorio)

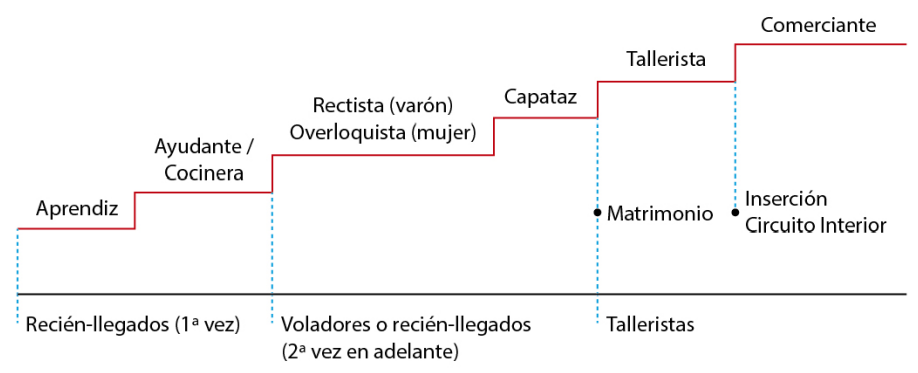

Fonte: elaboración propia.

Un sistema de capacitación precario es otra de las herramientas ideológicas en la producción del consentimiento. Si yo fuera un migrante y no un investigador quien se propuso a intercambiar fuerza de trabajo por información relativa al proceso productivo del taller de costura, hubiera podido empezar a cobrar por prenda confeccionada después de treinta minutos de capacitación. De hecho, empecé la etnografía en calidad de chuequista. El término se refiere a los rectistas aprendices que en lugar de hacer costuras rectas, las hacen chuecas, según el lenguaje del taller propuesto por el Colectivo Simbiosis, de Argentina ${ }^{23}$. Media hora fue lo que duró mi periodo de capacitación, echando mano de algunos retazos de tela inservibles que me fueron proporcionados por parte de

\footnotetext{
${ }^{22}$ Jerga de los talleres para definir la condición de la mujer en el proyecto migratorio en pareja.

${ }^{23}$ CUSICANQUI, op. cit.
} 
la pareja tallerista. Ante la aparente complejidad de manejar una máquina de costura para quienes no lo hacen, el cortísimo periodo de capacitación revela la apertura de este mercado laboral a los migrantes sin calificación previa. Eso no significa tener las habilidades para ensamblar prendas de vestir de manera rápida y eficiente, pero permite una primera inserción laboral casi inmediata.

\subsection{El juego en el proceso productivo y circulatorio}

Para finalizar los elementos que componen la base ideológica de la producción del consentimiento, quisiera analizar en separado la función que el juego ejerce en el taller. El juego, en la forma como lo plantea Burawoy ${ }^{24}$, nasce de las propias relaciones de los trabajadores entre sí y con los miembros de la dirección de la empresa. En el taller mecánico de Chicago, donde hizo su etnografía, el juego practicado por los obreros consistía en manipular las relaciones sociales dentro del taller, por ejemplo entre el maquinista y su auxiliar, con vistas a reducir el tiempo entre una tarea y otra al producir una pieza. Es como si cada empleado ejecutara su propia estrategia en busca de mayores satisfacciones en el local de trabajo.

En el taller de costura con migrantes, una vez aprobado el paquete de prendas de vestir, el tallerista entra en acción y dicta las reglas, desde la forma cómo distribuir los diferentes modelos de prendas, a la forma de confección, que ocurre por adición o por cadena. Bajo la producción por cadena, la pareja es considerada como una unidad productiva, es decir, cobra como si fuera un sólo costurero. Pareciera una desventaja, pero se trata de un "costurero con cuatro brazos", lo que acelera la actividad diaria. Cuando por otro lado se echa mano del método de confección por adición, el tallerista contabiliza el pago que corresponde a cada quien, prenda por prenda. La pareja, en este caso, participa individualmente. Por lo mismo, la forma de confección por adición es en general aplicada a los costureros solteros.

Entre parejas, el ritmo de confección aumenta o disminuye dependiendo justamente de si hay otros modelos de prenda aguardando el ensamblaje. En caso de que así sea, la pareja no sólo aumenta el ritmo de producción para agarrar el paquete de prendas que sigue, sino para que ninguna otra pareja o costurero soltero tenga la oportunidad de hacerlo antes. En estos casos, la jornada laboral puede rebasar las quince horas establecidas previamente, es decir, además de trabajar de $7 \mathrm{~h}$ a $22 \mathrm{~h}$ como lo hacen cotidianamente, suelen confeccionar algunas horas más.

Así se expresa el juego, en el ámbito productivo. Le toca a la pareja o al costurero soltero decidir por aumentar su productividad o no. Es algo que depende de ellos mismos. Los conflictos entre parejas costureras no se hacen esperar. Se pelean entre sí por supuestas ventajas que les da el patrón

$\overline{24}$ BURAWOY, op. cit. 
al momento de distribuir las prendas, por costuras más o menos difíciles o entonces por prendas mejor o peor pagadas. De esta manera, redireccionan el conflicto desde el tallerista hacia sus propios pares.

Planteo que el juego en el ámbito productivo planteado por Burawoy, se extiende al ámbito circulatorio en el universo de los talleres de costura con migrantes en São Paulo. Es decir, no se opta sólo por confeccionar más prendas en más tiempo de trabajo. Se opta también por el momento a trasladarse entre Los Andes y São Paulo o, estando en la metrópoli, por buscar otro taller donde residir/trabajar, utilizando o no los vales en los fines de semana para entablar contactos con costureros y talleristas de otros talleres, especialmente en la Plaza Kantuta o en la Calle Coimbra.

Los migrantes andino-bolivianos antes solían ingresar a Brasil vía el Chaco paraguayo, a raíz del menor control de los agentes migratorios en las carreteras que llevan a São Paulo. También solían adquirir una visa de turista, obtenida justamente en el cruce fronterizo, la cual tan sólo les permite una estancia de tres meses, sin permiso de trabajo. Dadas las facilidades de regularización migratoria del Acuerdo Mercosur de 2009, han pasado a utilizar la vía Corumbá, sin la necesidad de cruzar el Paraguay, según relatos recogidos por Cortes $^{25}$. Este autor revela que la regularización en tanto mecanismo utilizado para poder circular no necesariamente es utilizado para obtener derechos laborales, fortaleciendo la idea de que las condiciones de trabajo no-libre no están en tela de juicio. De esta forma, los migrantes se regularizan, cuando lo hacen, para poder seguir circulando en condición asalariada no-libre, y no para insertarse en empleos regulares, con beneficios previstos en ley y durante jornadas laborales regulares de ocho horas.

En los términos que yo he planteado hasta aquí, la agencia de individuos tanto en los momentos productivos como en los momentos circulatorios puede hacer la diferencia cuando el costurero se ve enfrentado a aspectos coercitivos en el taller, es decir, con actitudes y con dinámicas no previstas en el acuerdo tácito con el tallerista. Cualquier inconformidad por parte del costurero emanará de rupturas de este acuerdo, que intercambia fuerza de trabajo por techo, comida y pago por prenda. Esto pone de relieve que la restricción de su circulación de lunes a viernes no está en tela de juicio, es decir, tanto el derecho de piso como el sistema de cama-caliente y los vales no son cuestionados por parte de los costureros migrantes. Se les da por sentado y, por lo tanto, generan consentimiento.

Aunque supeditados a reglas que limitan su radio de acción, estos migrantes están en condiciones de elegir en primer lugar la mejor ruta según los riesgos que quieran asumir (vía Corumbá o vía Paraguay), así como el mejor momento para

${ }^{25}$ Cf. CORTES, op. cit. 
emprender el recorrido a São Paulo (o a Bolivia) de acuerdo a los periodos más o menos favorables de la industria de la moda. Desde luego, llegar a São Paulo durante los meses de septiembre a octubre, cuando la demanda de confección es alta, supone igualmente más horas sentados a la máquina de costura, así como ritmos de trabajo aún más intensos. Lo que se cobra en esos periodos supuestamente compensa el esfuerzo y las secuelas negativas a la salud. Para Cortes, "pareciera que los migrantes 'se adaptan de mejor manera' a esa estacionalidad que los brasileños, una vez que la migración es planificada de acuerdo a ella"26.

Para Cusicanqui ${ }^{27}$, son compensaciones diferidas en el tiempo. Se adhiere a privaciones de este carácter apostando a la conformación de un taller propio en el futuro, o a la posibilidad de ahorrar dinero, según los planes de cada individuo o familia migrante. Tener garantizados techo, comida, agua y energía eléctrica, poder tener ingresos sin depender de nadie más que el propio esfuerzo, poder circular entre Bolivia, Paraguay y Brasil de acuerdo a la estacionalidad de la moda, y poder cambiar de taller de costura (de manera negociada o no), son aspectos que refuerzan la adhesión a la condición de trabajo no-libre tal cual se manifiesta en los talleres de costura con migrantes.

Presento la sistematización gráfica que contempla los tres pilares materiales de la producción del consentimiento (derecho de piso, cama-caliente y vales), y los pilares ideológicos (mercado laboral interno y la dinámica del juego). Este esquema abarca la capacidad de accionar que el migrante tiene sobre cada uno de sus elementos (véase Figura 2).

\section{Figura 2 - Mecanismos de producción del consentimiento (productivo y circulatorio)}
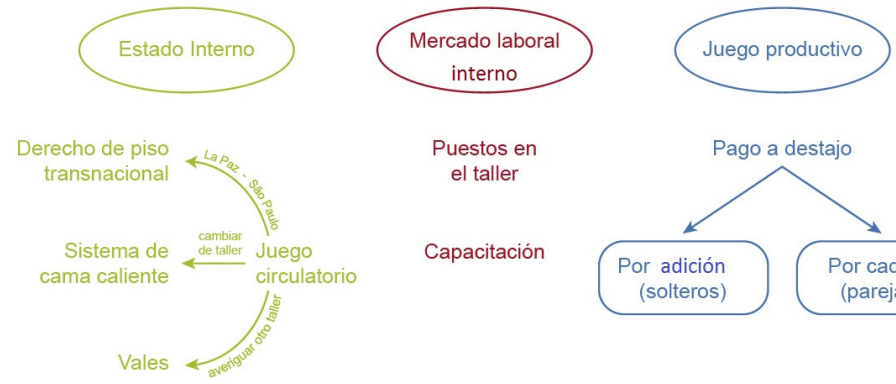

Fonte: elaboración propia.

\section{A modo de conclusión}

A lo largo de por lo menos veinticinco años, de manera masiva, el mecanismo expuesto anteriormente ha coadyuvado a impulsar la movilidad de grupos de migrantes por un territorio que abarca el altiplano boliviano,

\footnotetext{
${ }^{26}$ Ibidem, p. 76.

${ }^{27}$ CUSICANQUI, op. cit.
} 
incluyendo a ciudades como El Alto, La Paz, Oruro y Cochabamba, y al área metropolitana de São Paulo. Trabajos recientes también indican la continuidad de dicha movilidad por un territorio conosureño de dimensiones aún mayores, involucrando migrantes paraguayos ${ }^{28}$ y el área metropolitana de Buenos Aires ${ }^{29}$. Pareciera que así como el en conurbano paulista, los talleres de costura del conurbano bonaerense lo transforman en un territorio de atracción y de expulsión de migrantes sudamericanos, posiblemente permeado por relaciones laborales que también oscilan entre lo coercitivo y lo consentido.

Debido a la existencia de un acuerdo, aunque tácito, poco claro, entre los talleristas y los costureros, pero en el cual el empleado puede distinguir los niveles coercitivos de otros que no lo son, tratar el proceso de contratación y de empleo de costureros como trabajo esclavo borra la capacidad que el costurero tiene de romper el vínculo laboral, ya sea fugándose del taller o simplemente buscando otro local de trabajo. Esta misma capacidad es la que le permite definir los límites de su propia "esclavitud". Desde luego, no se trata de celebrar la participación del costurero migrante en su propia dominación, sino más bien enfocar aspectos de este proceso social relativos al consentimiento de estos grupos de migrantes. Son aspectos que sostienen estas relaciones que de otra forma no se mantendrían a lo largo de dos décadas y media si estuvieran sólo restrictas a arbitrariedades por parte del tallerista, como las amenazas físicas y psicológicas.

De ahí la relevancia de la noción de la producción del consentimiento como instrumento de mediación teórica que permite explicar la reproducción de un taller de costura, reclutando permanentemente a nuevos empleados a tres mil quilómetros de distancia y otros voladores en São Paulo. Además, los acuerdos entre empleadores y empleados se empalman con el funcionamiento del propio mercado de la ropa.

De las formas generales de trabajo no-libre, expresadas en el vínculo por deuda, en el adelanto de salario en efectivo y en el aprendizaje, traté de recorrer el camino que lleva a las formas concretas que se dan en el taller de costura. Es así que la tríada compuesta por el derecho de piso transnacional, el sistema de cama-caliente y los vales, permite que el costurero se traslade entre Bolivia y Brasil de manera pendular, sin tener que preocuparse con transporte, techo y comida. El mecanismo también ayuda a explicar cómo los miles de talleres de costura del conurbano paulista han podido mantenerse en condiciones de fragmentación productiva intensa ${ }^{30}$, haciendo frente a las eventuales crisis económicas, así como a la llegada de prendas de vestir confeccionadas en China a precios muy abajo del promedio practicado localmente.

\footnotetext{
${ }^{28}$ Cf. FREIRE DA SILVA, Carlos, CORTES, Tiago Rangel. Dossiê - Paraguaios. Travessia, revista do migrante, ano XXVII, n. 74, São Paulo, 2014.

${ }^{29}$ Cf. BENENCIA, op. cit.; cf. FREITAS, op. cit.

${ }^{30}$ Cf. FREIRE da SILVA, op. cit.
} 


\section{Bibliografía}

BENENCIA, Roberto. El infierno del trabajo esclavo. La contracara de las "exitosas" economías étnicas. Avá, n. 15, 2009, p. 43-72.

BRASS, Tom. Labour Regime Change in the Twenty-First Century: Unfreedom, Capitalism and Primitive Accumulation. Boston: Brill, 2011.

BURAWOY, Michael. El consentimiento en la producción. Los cambios del proceso productivo en el capitalismo monopolista. Madrid: Ministerio de Trabajo y Seguridad Social, 1989.

CORTES, Tiago. Os migrantes da costura em São Paulo: retalhos de trabalho, cidade e Estado. Tesis de Maestría, USP, 2013.

CUSICANQUI, Silvia Rivera et alii. De chuequistas y overlockas: una discusión en torno a los talleres textiles. Buenos Aires: Tinta Limón, 2011.

FREITAS, Patricia de. Projeto costura. Percursos sociais de trabalhadores migrantes, entre a Bolívia e a indústria de confecção das cidades de destino. Tesis de Doctorado, UNICAMP, 2014.

FREIRE DA SILVA, Carlos. Trabalho Informal e Redes de Subcontratação: Dinâmicas Urbanas da Indústria de Confecções em São Paulo. Tesis de Maestría, USP, 2008.

MCGRATH, Siobhán. Unfree labor, capitalism and contemporary forms of slavery. Spring, 2005. Disponível em: < http://docplayer.net/24200000-Unfree-laborcapitalism-and-contemporary-forms-of-slavery-siobhan-mcgrath-graduatefaculty-of-political-and-social-science-new-school-university.html> .

MOULIER-BOUTANG, Yann. Formes de travail non libre. Accumulation primitive: préhistoire ou histoire continuée du capitalisme? Cahiers d'études africaines, n. 179-180, 2005, p. 1069-1092.

SILVA, Sidney Da. A migração dos símbolos: diálogo intercultural e processos identitários entre os bolivianos em São Paulo. São Paulo em Perspectiva, v. 19, n. 3, jul-set 2005, p. 77-83.

SOUCHAUD, Sylvain. A confecção: nicho étnico ou nicho econômico para a imigração latinoamericana em São Paulo? In BAENINGER, Rosana (org.). Imigração Boliviana no Brasil. Campinas: Nepo/Unicamp, Fapesp, CNPq, Unfpa, 2012, p. 75-92.

Recibido para publicación en 30.01.2017

Aceptado para publicación en 15.02.2017

Received for publication in January 30 ${ }^{\text {th }}, 2017$

Accepted for publication in February 15 th 2017

ISSN impresso 1980-8585

ISSN eletrônico 2237-9843

http://dx.doi.org/10.1590/1980-85852503880004911 